\title{
Association of Total and High Molecular Weight Adiponectin with Components of Metabolic Syndrome in Mexican Children
}

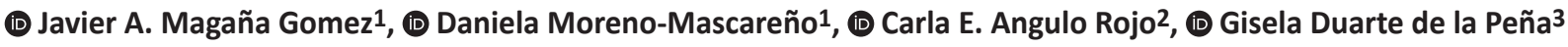 \\ 1 Universidad Autónoma de Sinaloa, Escuela de Nutrición y Gastronomía, Sinaloa, México \\ ¿Universidad Autónoma de Sinaloa, Facultad de Medicina, Centro de Investigación Aplicada a la Salud Pública, Laboratorio de Neurociencias, \\ Sinaloa, México \\ 3Universidad Autónoma de Occidente, Programa de Nutrición, Sinaloa, México
}

\section{What is already known on this topic?}

Childhood obesity is related to several impaired biochemical parameters, including the concentration of total- and high molecular weight-adiponectin. A low adiponectin concentration was strongly associated with the prevalence of metabolic syndrome.

\section{What this study adds?}

The strong inverse correlation between adiponectin levels and biochemical parameters related to carbohydrate metabolism, contribute to the hypothesis that low adiponectin levels are associated with an elevated risk of diabetes. This reinforces the early role of insulin resistance in future vascular events. The circulating concentration of total adiponectin may represent an excellent biomarker to evaluate the risk of metabolic complications in young children.

\section{Abstract}

Objective: Childhood obesity linked to metabolic alterations, tend to appear simultaneously with altered adipocytokines, suggesting a role in pathogenetic development. Low circulating level of total and high molecular weight (HMW) adiponectin have been associated with components of the metabolic syndrome (MetS) and could represent an independent risk factor with potential use as a biomarker. To examine the prevalence of MetS in Mexican school children and to investigate the association of total and HMW adiponectin levels with biochemical parameters related to MetS.

Methods: The study included a population of boys and girls, from 8 to 11 years old. Anthropometric and biochemical parameters were evaluated according to weight and MetS status. A correlation analysis was fitted to establish an association between adiponectin concentrations and metabolic indicators.

Results: One-hundred and fifty five children participated (59.4\% females) from 8-11 years of age. The prevalence of MetS was of $10.3 \%$. Impaired biochemical parameters, including total and HMW adiponectin, were associated with obesity. The adiponectin level was significantly lower in MetS than in non-MetS subjects (4.5 vs. $5.4 \mu \mathrm{g} / \mathrm{mL}$ ). Total- but not HMW adiponectin concentration was negatively correlated with blood pressure, fasting insulin, fasting blood sugar and Homeostatic Model Assessment for Insulin Resistance.

Conclusion: In young children, the total adiponectin level is associated with impaired biochemical parameters of carbohydrate metabolism and could be an excellent early predictor of metabolic complications.

Keywords: Adiponectin, children, insulin resistance, metabolic syndrome, obesity

\section{Introduction}

Childhood obesity is a complex disorder, linked to metabolic and clinical abnormalities, such as insulin resistance, dyslipidemia, and hypertension. Various combinations of these impaired metabolic functions, even in children, have been used to define the metabolic syndrome (MetS) (1). The simultaneous occurrence of obesity and impaired metabolic functions demonstrates that the accumulation of adipose tissue is a frequent etiologic basis. Adipose tissue secretes 
numerous physiologically active peptides with properties similar to cytokines, commonly known as adipocytokines, such as leptin, interleukin-6, resistin, and adiponectin. While most of the adipocytokines promote dysregulated metabolism, adiponectin contributes to maintaining energy balance, insulin sensitivity, blood pressure, immunological processes, angiogenesis, fat metabolism, and homeostasis. When adiponectin levels are low, as occurs in central obesity, the risk for metabolic alterations increases in adults, adolescents, and children $(2,3,4)$.

Circulating adiponectin exists as multimers of high-, medium-, and low-molecular-weight (HMW, MMW, and LMW, respectively), with predominantly HMW and LMW isoforms. In adults, low HMW adiponectin concentration reflects metabolic abnormalities related to obesity, insulin resistance, and vascular alterations more specifically than total-adiponectin (5).

Multifactorial disorders, such as MetS, may be affected by characteristics of the study population. In Japanese children, HMW adiponectin was inversely correlated with obesity and insulin resistance (6). Although the Mexican population is a heterogeneous genetic mix, significant heritability for adiponectin and obesity traits substantiate a genetic contribution to circulating cytokine levels in Hispanic children $(7,8)$. Furthermore, the age profile of the population is an important factor related to the pathophysiology of MetS and adiponectin concentration (9). Therefore, this study was designed to investigate the association of total and HMW adiponectin levels with components of the MetS, and its possible role as an early risk marker in young Mexican children.

\section{Methods}

\section{Subjects}

Children between the ages of 8 and 11 were randomly selected to participate in a cross-sectional study from six representative elementary schools in five districts in a northwestern urban region of Mexico. Schools were selected from lists made available by the Educational Authorities, according to its geographical location. The protocol was presented to the school board, classrooms were selected, and parents were required to sign a written consent form to allow their children to participate. Children without medical therapy, with parental permission and who had fasted, were eligible for the study. The study protocol was approved by the Research Ethics Committee of the Faculty of Medicine, Autonomous University of Sinaloa, with registration number CONBIOÉTICA-25-CEI-003-20181012. All study procedures were in accordance with the 1964 Helsinki Declaration and its later amendments or comparable ethical standards. Volunteers were informed about the aim of the study, and written consent was obtained from their legal guardians.

\section{Anthropometric Variables}

Anthropometric variables were measured according to standardized procedures (10). Body weight (BW) was measured with children wearing lightweight clothing and no shoes, to the nearest $0.1 \mathrm{~kg}$ using a standardized electronic digital scale (Tanita BC-553; Illinois, USA). Height was measured to the nearest $0.1 \mathrm{~cm}$ using a portable stadiometer (Seca-214; Hamburg, Germany) with the head in the Frankfort horizontal plane. Waist circumference (WC) was measured with a non-elastic, flexible measuring tape at the mid-point between the iliac crest and the lower edge of the ribs at the end of a normal expiration. Body mass index (BMI; $\mathrm{kg} / \mathrm{height}$ in $\mathrm{m}^{2}$ ) was calculated and classified according to the age- and gender-specific cut-off points proposed by the World Health Organization (WHO) (11).

\section{Clinical and Metabolic Parameters}

Systolic and diastolic blood pressures were obtained from the right arm with the child seated, after rest, using a digital sphygmomanometer and appropriately sized cuff. Venous blood samples were collected in the morning (8:00 to 9:00 am) by direct venipuncture after an overnight (10 to 12 hour) fast. Plasma and serum were separated by centrifugation, aliquoted, and immediately frozen at $-80{ }^{\circ} \mathrm{C}$ for later analysis. Glucose oxidase method (RANDOX Laboratories Ltd., Antrim, UK) was used to quantify fasting blood glucose levels. Triglyceride (TG), total cholesterol (TChol), highdensity lipoprotein cholesterol (HDL-C) and low-density lipoprotein cholesterol (LDL-C) were measured using an enzymatic colorimetric method (RANDOX Laboratories Ltd., Antrim, UK). Insulin, total- and HMW-adiponectin, were measured by enzyme-linked immunosorbent assay using commercially available kits (ALPCO Immunoassays; $\mathrm{NH}$, USA). Assays were conducted according to recommendations of the fabricant.

\section{Classification of Pediatric MetS}

Currently, a standardized definition for MetS exists for adults, but not for children and adolescents. Therefore, modified WHO criteria were applied to diagnose MetS in children (12). This pediatric/adolescent definition requires either insulin resistance, hyperglycemia, or known diabetes plus the presence of two out of three other risk parameters: hypertension (elevated age/gender systolic and/or diastolic blood pressure $\geq 90^{\text {th }}$ percentile), dyslipidemia (hypertriglyceridemia $\geq 150 \mathrm{mg} / \mathrm{dL}$ or low-serum HDL-C $<39$ or $<35 \mathrm{mg} / \mathrm{dL}$ in boys and girls, respectively), and central 
obesity (age/gender $W C \geq 90^{\text {th }}$ percentile or $B M I \geq 95^{\text {th }}$ percentile). The cut-offs for impaired fasting glucose were either $\geq 100 \mathrm{mg} / \mathrm{dL}$ or fasting insulin $\geq 75^{\text {th }}$ percentile (13). Insulin resistance was defined using the homeostasis model assessment for insulin resistance (HOMA-IR), calculated as the product of the fasting plasma insulin level $(\mu \mathrm{UI} / \mathrm{mL})$ and the fasting plasma glucose level ( $\mathrm{mmol} / \mathrm{L})$, divided by 22.5 (14).

\section{Statistical Analysis}

The distribution of data was assessed using the normality test Kolmogorov-Smirnov with Lilliefors correction. Data are presented as the means \pm standard deviation. T-test was used for comparison of continuous variables where applicable and by ANOVA with Tukey-Kramer post hoc comparison being used to evaluate group differences. For the variables without normal distribution, Kruskal-Wallis test for independent samples, according to BMI classification, was performed. Boys and girls were combined in the same groups because there were no significant sex-related differences in the anthropometric and biochemical data in the obese and nonobese children. Total- and HMW-adiponectin were correlated to anthropometric, biochemical, and clinical parameters using the Pearson or Spearman correlation coefficient. The statistical differences were considered significant at $p<0.05$. All statistical analyses were performed using the statistical software NCCS v.2007 (15).

\section{Results}

The initial population consisted of 294 children, of whom 85 were excluded for not meeting the inclusion criteria or declined to participate, thus the drop out rate was $28.9 \%$. On the day of blood sampling, 44 children were eliminated for not having parental permission or not being fasted, another ten were dismissed for failing to obtain the blood sample because of stress at the moment of sampling. There were no cases of children on medication or kidney disease excluded from the study. This resulted in a study cohort of 155 children (59.4\% of females): 75 of healthy weight, 37 overweight, and 43 obese (Figure 1). The prevalence of MetS was $10.3 \%$, according to the modified WHO definition. At the initial analysis, children showed no significant sex-related differences in the anthropometric and biochemical data; therefore, they were combined in the same groups. Characteristics of subjects and comparisons of mean values of clinical and metabolic continuous variables were analyzed according to obesity status (Table 1). Age was similar $(p>0.05)$ between groups. In the obesity group, insulin and adiponectin had statistically higher concentrations $(p<0.05)$, while HDL-C, total- and
HMW-adiponectin were lowest. Also, blood pressure was higher in the obesity group.

When comparisons were made according to the presence or absence of MetS (Table 2), there was no difference for age ( $p>0.05)$. However, weight, BMI, and WC were different between groups $(p<0.0001)$ with the highest values in the group with MetS. Insulin, HOMA-IR, LDL-C, TG, and blood pressure were significantly higher in the MetS group, while total adiponectin and HDL were significantly lower. Fasting blood glucose concentration, TChol, and HMW-adiponectin did not differ between the two groups.

Absolute values of adiponectin were tested by correlation analysis, and total-adiponectin had a significant negative correlation with anthropometric parameters and biochemical variables related to carbohydrate metabolism but not with those of the lipid metabolism (Table 3). In addition, a significant inverse correlation was found between totaladiponectin and the number of MetS components present. HMW-adiponectin was inversely correlated with weight, BMI, and HDL-C although no other significant correlation was found for the other parameters examined (Table 3).

\section{Discussion}

The increase in childhood obesity worldwide is recognized as one of the most severe public health problems. The evidence of the association between childhood obesity and parameters of MetS is increasing $(7,16,17)$. Adipocytokines and genetic background are known to be important in the pathogenesis of MetS $(18,19)$. In the present study, we assessed the impact of childhood obesity and MetS in young

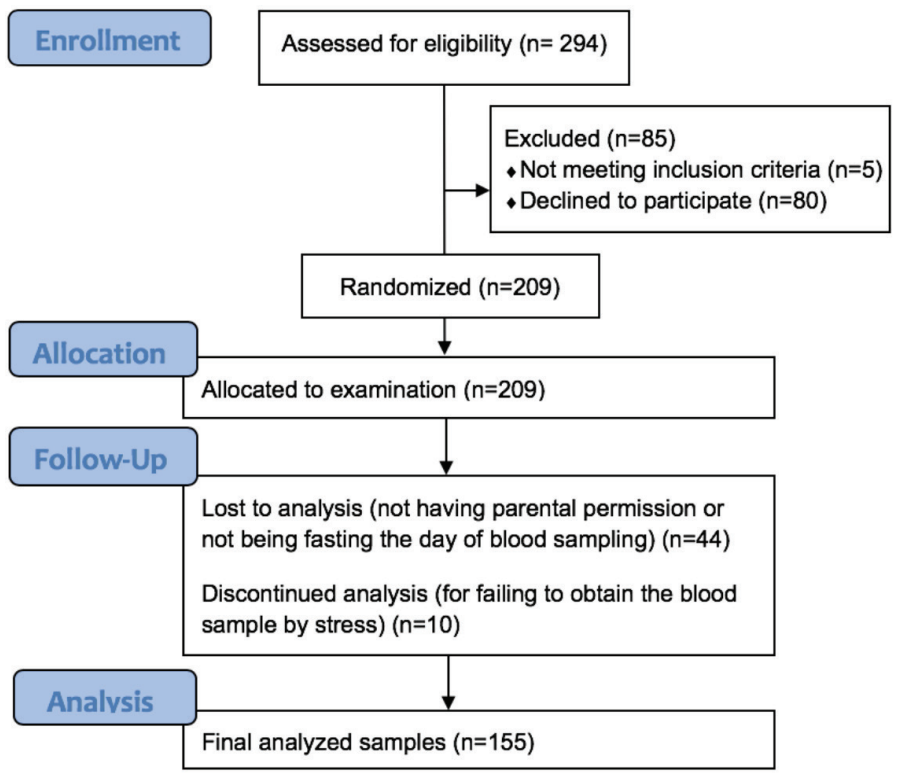

Figure 1. Flow chart of the recruitment stage of the study 
Mexican children and its association with total- and HMW adiponectin.

Using the WHO definition, the prevalence of MetS found in this study (10.3\%) was higher for the general child population compared with that found in other populations (3\% to $8.4 \%)(20,21,22)$. However, it is difficult to contrast the prevalence of MetS because modified and non-standard definitions have been used and no globally accepted set of criteria exist for defining MetS in the pediatric/adolescent population. The prevalence of MetS in children and adolescents, based on the National Cholesterol Education Program's Adult Treatment Panel 3 definition, tends to give higher prevalences and has been reported to vary from $4.2 \%$ to $18.6 \%$, and in a similarly aged population (7-9 years old) to our study it was $15.8 \%(23,24,25,26)$. This increased prevalence highlights the importance of early diagnose of MetS in childhood, to prevent the progression from obesity to insulin resistance, cardiovascular disease, and type 2 diabetes.

The analysis of anthropometric variables according to weight status has confirmed that each component of the MetS worsens with increasing weight, independent of sex (27). As has been reported previously $(26,28,29)$ and was found in our study, several parameters did not show significant differences between overweight and obese children, except for a significantly higher WC in the obese group, which reinforces its importance as a risk indicator. The impaired levels of insulin, HOMA-IR, TG, HDL-C, and total- and HMW-adiponectin in the obese group compared to the normal group confirm the remarkable impact of obesity on metabolic disorders. Compared to normal and overweight children, obese children have a higher prevalence of many components of MetS. This pattern is similar to other studies in obese children and adolescents,

Table 1. Comparison of anthropometric, biochemical, and clinical characteristics of the study participants according to obesity status

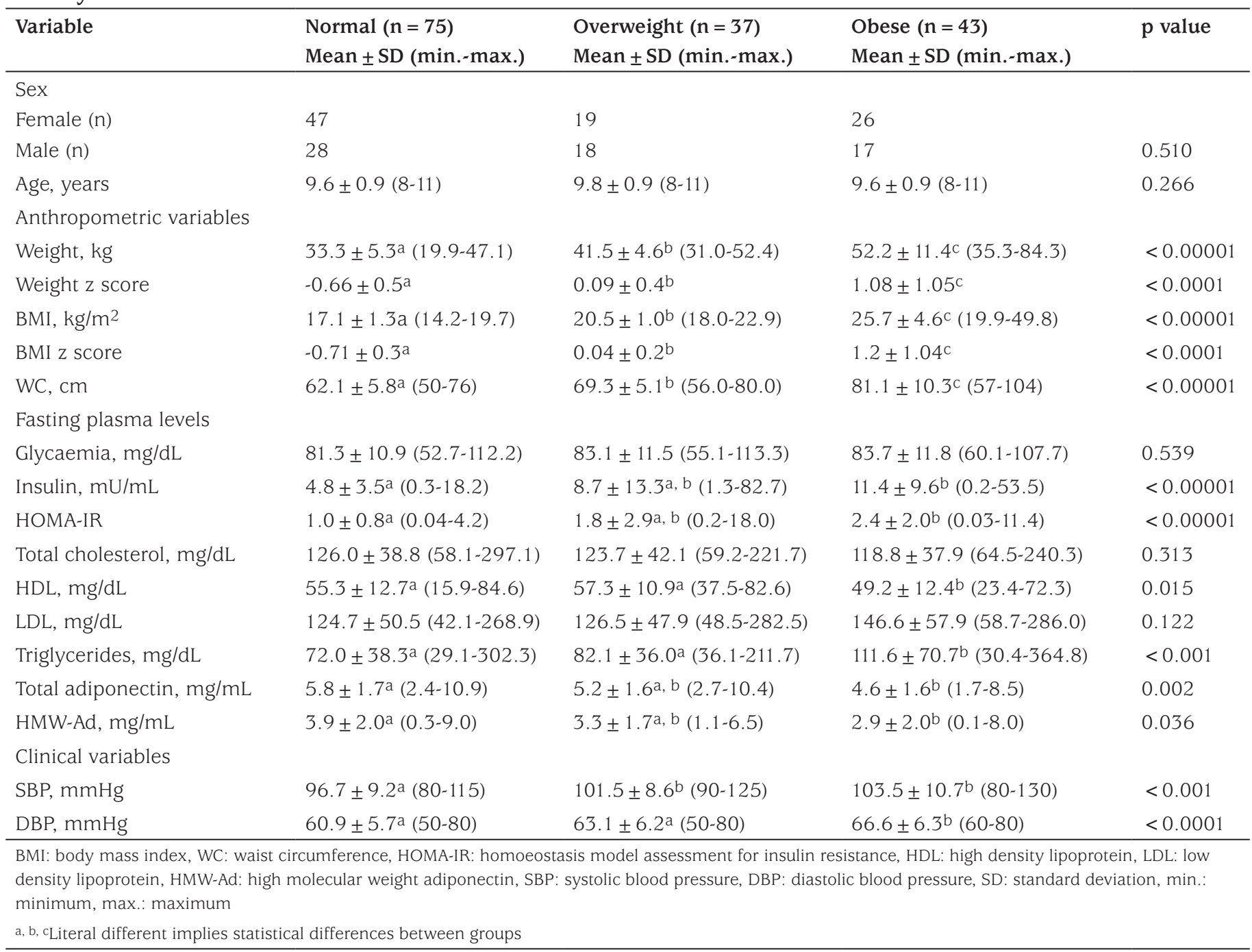


Table 2. Comparison of anthropometric, biochemical, and clinical characteristics of the study participants according to the presence or absence of metabolic syndrome

\begin{tabular}{|c|c|c|c|}
\hline & $\begin{array}{l}\text { Without MetS }(n=139,89.7 \%) \\
\text { Mean } \pm \text { SD (min. }-\max .)\end{array}$ & $\begin{array}{l}\text { With MetS }(\mathrm{n}=16,10.3 \%) \\
\text { Mean } \pm \mathrm{SD}(\min .-\max .)\end{array}$ & $\mathrm{p}$ value \\
\hline Age, years & $9.6 \pm 0.9(8-11)$ & $9.8 \pm 0.7(8-11)$ & $>0.05$ \\
\hline \multicolumn{4}{|l|}{ Anthropometric variables } \\
\hline Weight, kg & $38.2 \pm 8.2(19.9-68.8)$ & $60.3 \pm 10.9(39.9-84.3)$ & $<0.0001$ \\
\hline Weight z score & $-0.21 \pm 0.76$ & $1.8 \pm 1.0$ & $<0.0001$ \\
\hline BMI, kg/m² & $19.3 \pm 3.1(14.2-29.4)$ & $28.2 \pm 6.3(23.9-49.9)$ & $<0.0001$ \\
\hline BMI z score & $-0.21 \pm 0.69$ & $1.8 \pm 1.4$ & $<0.0001$ \\
\hline $\mathrm{WC}, \mathrm{cm}$ & $66.9 \pm 8.8(50.0-94.0)$ & $87.1 \pm 8.9(72.0-104.0)$ & $<0.0001$ \\
\hline \multicolumn{4}{|l|}{ Fasting plasma levels } \\
\hline Glycaemia, mg/dL & $82.1 \pm 11.2(52.7-113.3)$ & $84.9 \pm 12.0(64.4-107.6)$ & $>0.05$ \\
\hline Insulin, mU/mL & $6.7 \pm 8.7(0.2-82.6)$ & $15.4 \pm 6.9(8.3-32.8)$ & $<0.001$ \\
\hline HOMA-IR & $1.4 \pm 1.9(0.03-18.0)$ & $3.2 \pm 1.4(1.7-7.4)$ & $<0.0001$ \\
\hline Total cholesterol, mg/dL & $123.5 \pm 37.8(58.1-297.0)$ & $122.9 \pm 51.8(76.8-240.3)$ & $>0.05$ \\
\hline $\mathrm{HDL}, \mathrm{mg} / \mathrm{dL}$ & $55.5 \pm 11.9(15.9-84.6)$ & $42.2 \pm 12.5(23.4-64.2)$ & $<0.0001$ \\
\hline LDL, mg/dL & $127.5 \pm 48.4(42.1-282.6)$ & $163.7 \pm 75.3(67.6-286.0)$ & $<0.01$ \\
\hline Triglycerides, mg/dL & $76.4 \pm 38.2(29.1-302.3)$ & $163.8 \pm 80.7(73.5-364.9)$ & $<0.0001$ \\
\hline Total adiponectin, mg/mL & $5.4 \pm 1.7(2.2-10.9)$ & $4.5 \pm 1.5(1.7-6.8)$ & $<0.05$ \\
\hline HMW-Ad, mg/mL & $3.4 \pm 1.9(0.08-9.0)$ & $3.5 \pm 2.1(1.3-8.0)$ & $>0.05$ \\
\hline \multicolumn{4}{|l|}{ Clinical variables } \\
\hline $\mathrm{SBP}, \mathrm{mmHg}$ & $98.8 \pm 9.7(80-125)$ & $107.5 \pm 8.4(100-130)$ & $<0.001$ \\
\hline DBP, mmHg & $62.4 \pm 6.2(50-80)$ & $67.8 \pm 6.3(60-80)$ & $<0.01$ \\
\hline
\end{tabular}

\begin{tabular}{|c|c|c|c|c|}
\hline Variable & Total adiponectin & $p$ value & HMW adiponectin & $p$ value \\
\hline Weight, kg & -0.377 & $<0.0001$ & -0.189 & $<0.05$ \\
\hline BMI, kg/m² & -0.340 & $<0.0001$ & -0.198 & $<0.05$ \\
\hline $\mathrm{WC}, \mathrm{cm}$ & -0.310 & $<0.001$ & -0.101 & $>0.05$ \\
\hline Glycaemia, mg/dL & -0.280 & $<0.001$ & -0.043 & $>0.05$ \\
\hline Insulin, mU/mL & -0.171 & $<0.001$ & -0.085 & $>0.05$ \\
\hline HOMA-IR & -0.175 & $<0.001$ & -0.077 & $>0.05$ \\
\hline Total cholesterol, mg/dL & 0.028 & $>0.05$ & 0.116 & $>0.05$ \\
\hline HDL-C, mg/dL & 0.113 & $>0.05$ & 0.171 & $<0.05$ \\
\hline LDL-C, mg/dL & 0.015 & $>0.05$ & -0.002 & $>0.05$ \\
\hline Triglycerides, mg/dL & -0.076 & $>0.05$ & 0.120 & $>0.05$ \\
\hline SBP, mmHg & -0.116 & $>0.05$ & -0.066 & $>0.05$ \\
\hline DBP, mmHg & -0.136 & $>0.05$ & 0.027 & $>0.05$ \\
\hline No. of MetS components & -0.279 & $<0.001$ & -0.109 & $>0.05$ \\
\hline
\end{tabular}


in which low serum adiponectin levels were associated with markers of MetS, such as hyperglycemia, hyperinsulinemia, high blood pressure, and dyslipidemia $(2,25,30)$.

When comparing our cohort, stratified by the presence or absence of MetS, there is a suggestion that the prevalence of MetS increases directly with BMI. Similar to Turkish and Portuguese children with MetS and obese Italian children, in our study, no differences were observed in TChol level, suggesting that this indicator is less critical in this age group $(24,31,32)$. However, in Korean children, an association between non-HDL cholesterol and MetS has been reported (33).

Regarding biochemical parameters, total-adiponectin had the strongest inverse correlation respect to HMW adiponectin, with glycaemia, followed by number of MetS components, HOMA-IR and insulin concentration. Similar findings have been described, where total adiponectin had a significant inverse relation with HOMA-IR and obesity, and its low concentration was an essential determinant of insulin sensitivity and HDL in children and may predict type 2 diabetes $(7,29,32,34,35)$. No significant correlation was found for biochemical parameters related to fat metabolism (e.g., TG, HDL-C, LDL-C and TChol), probably due to the young age of the population and the pathophysiology of MetS (24,36). Longitudinal studies showed that blood pressure and TG decreased when HOMA decreases, independently of changes in BW, supporting the hypothesis that insulin resistance is the central abnormality contributing to these cardiovascular risk factors and development of atherosclerosis and MetS (24,29). The studies found that insulin resistance, or its accomplice, hyperinsulinemia could precede to dyslipidemia, enhancing the output of very-LDL and raising TG; this lipid overload in muscle is diverted to the liver, promoting fatty liver and atherogenic dyslipidemia (37). These mechanisms affecting lipid metabolism could be at an early stage in our young population where, instead, we observed impaired glucose homeostasis as the principal affliction (38). These results obtained in the present study, support the early observations about the need to include insulin resistance, as proposed in the WHO criteria, for the diagnosis of MetS in children $(23,31,39,40)$.

A protective role of adiponectin is evident early in life and compromised in youth-onset obesity, and low concentrations could be considered a risk factor $(7,32,34)$. It has been suggested that low levels of adiponectin are involved in the association between childhood obesity and adult atherosclerosis (41). In the present study, total- and HMW-adiponectin were decreased in obese children and correlated with anthropometric variables (weight and BMI). However, whereas Total-adiponectin correlated with several biochemical parameters, HMW-adiponectin only correlated with HDL-C. Previous studies have found that sub-fractions of adiponectin have different biological effects, but their degree of association may vary according to the characteristics of the population, such as the different age groupings included in the studies $(42,43)$. Adiponectin levels decline with age in association with changes in sex hormones and growth factors. Among growing youth, total fat mass is the primary determinant of adiponectin concentrations, and the age effect is mostly a result of increased fat mass with increased age $(44,45)$. Consistent with the above, changes in total- and HMW-adiponectin levels in childhood obesity is different to that in elderly obese patients (46). Therefore, the relationship between adiponectin and the biochemical parameters of dyslipidemia may not be established until puberty (47).

Besides, the association of HMW adiponectin with MetS indicators seems to be influenced by adiposity (48). In obese prepubertal children, HMW adiponectin shows a closer relationship with the improvement of carbohydrate metabolism parameters than with body fat content. Other studies confirm that the relationships of plasma adiponectin with a favorable lipid profile depend on adiposity and that central obesity plays a significant role in the relationships of adiponectin with TG. These findings may mean that adiponectin may not necessarily play a favorable role in lipid metabolism, and it might have multiple effects on this metabolic process based on the underlying condition. Different studies have demonstrated that adiponectin concentrations have ethnic variance and were lower in Asian as compared to African-American children, were positively related to insulin sensitivity and HMW-adiponectin was not superior in predicting metabolic variables $(49,50,51)$. Our data indicate that, in the context of the MetS in Mexican children, HMW-adiponectin might not have the same degree of relevance. Hence, the relationships between adiponectin levels and anthropometric and biochemical indicators in children appear to be independent of sex and influenced by ethnicity and lifestyles associated with modernization. We suggest that the genetic backgrounds of cohorts should also be considered in future studies and body composition analysis should be more detailed in order to investigate the relevance of adiponectin in pathogenesis of pediatric MetS.

\section{Study Limitations}

Limitations of our study are mostly due to the limited sample size and its cross-sectional nature. However, our findings are consistent with the idea that ethnic differences influence the distribution of adiponectin isoforms and their relationship with metabolic parameters. 


\section{Conclusion}

Childhood obesity is related to several impaired biochemical parameters, including the concentration of total- and HMWadiponectin. A low adiponectin concentration was related closely to the prevalence of MetS. The strong inverse correlation between adiponectin levels and biochemical parameters related to carbohydrate metabolism, contribute to the hypothesis that low adiponectin levels are associated with an elevated risk of diabetes. The absence of correlation between total- and HMW-adiponectin and fat metabolism indicators could be explained by the young age of the study population. Furthermore, it reinforces the importance of early insulin resistance in development of the MetS and possibly future vascular events. Therefore, circulating concentration of total adiponectin may represent an excellent biomarker to evaluate the risk of metabolic complications in young Mexican children. Additionally, a consensual pediatric definition of MetS is needed in order to better compare between studies and populations, and adequate screening and evaluation of children at risk or with MetS.

\section{Acknowledgements}

We are grateful to all the staff of the research group and Juan Hurtado and Rosario Mascareño for their technical assistance when collecting blood samples and to Dr. Martha Belury for critical review of this Manuscript.

\section{Ethics}

Ethics Committee Approval: The study protocol was approved by the Research Ethics Committee of the Faculty of Medicine, Autonomous University of Sinaloa, with registration number CONBIOÉTICA-25-CEI-003-20181012.

Informed Consent: Volunteers were informed about the aim of the study, and written consent was obtained from their legal guardians.

Peer-review: Externally and internally peer-reviewed.

\section{Authorship Contributions}

Concept: Javier A. Magaña Gomez, Design: Carla E. Angulo Rojo, Data Collection or Processing: Daniela MorenoMascareño, Analysis or Interpretation: Gisela Duarte de la Peña, Javier A. Magaña Gomez, Literature Search: Daniela Moreno-Mascareño, Carla E. Angulo Rojo, Writing: Daniela Moreno-Mascareño, Carla E. Angulo Rojo, Javier A. Magaña Gomez.

Financial Disclosure: This study was supported by a grant from the Mexican Government, through the Programa de Mejoramiento del Profesorado (PROMEP), grant PROMEP/103.5/10/4512.

\section{References}

1. Friedemann C, Heneghan C, Mahtani K, Thompson M, Perera R, Ward AM. Cardiovascular disease risk in healthy children and its association with body mass index: systematic review and meta-analysis. BMJ 2012;345:e4759.

2. Liu YL, Liang HR, Liu HT, Li SY, Zhou YY, Cheng HL, Zhou LS. Association of serum adiponectin levels with artherosclerosis and the metabolic syndrome in obese children. J Pediatr Endocrinol Metab 2010;23:743751.

3. El-Wakkad A, Hassan Nel-M, Sibaii H, El-Zayat SR. Proinflammatory, anti-inflammatory cytokines and adiponkines in students with central obesity. Cytokine 2013;61:682-687. Epub 2013 Jan 8

4. Abseyi N, Șıklar Z, Berberoğlu M, Hacıhamdioğlu B, Savaș Erdeve S, Öçal G. Relationships between osteocalcin, glucose metabolism, and adiponectin in obese children: Is there crosstalk between bone tissue and glucose metabolism? J Clin Res Pediatr Endocrinol 2012;4:182-188.

5. Nascimento H, Costa E, Rocha S, Lucena C, Rocha-Pereira P, Rego C, Mansilha HF, Quintanilha A, Aires L, Mota J, Santos-Silva A, Belo L. Adiponectin and markers of metabolic syndrome in obese children and adolescents: impact of 8-mo regular physical exercise program. Pediatr Res 2014;76:159-165. Epub 2014 May 12

6. Ochiai H, Shirasawa T, Nishimura R, Morimoto A, Ohtsu T, Hoshino $\mathrm{H}$, Tajima N, Kokaze A. High-molecular-weight adiponectin and anthropometric variables among elementary schoolchildren: a population-based cross-sectional study in Japan. BMC Pediatr 2012;12:139.

7. He J, Stryjecki C, Reddon H, Peralta-Romero J, Karam-Araujo R, Suarez F, Gomez-Zamudio J, Burguete-Garcia A, Alyass A, Cruz M, Meyre D. Adiponectin is associated with cardio-metabolic traits in Mexican children. Sci Rep 2019;9:3084.

8. Cai G, Cole SA, Butte NF, Smith CW, Mehta NR, Voruganti VS, Proffitt JM, Comuzzie AG. A genetic contribution to circulating cytokines and obesity in children. Cytokine 2008;44:242-247. Epub 2008 Oct 10

9. Mirza S, Hossain M, Mathews C, Martinez P, Pino P, Gay JL, Rentfro A, McCormick JB, Fisher-Hoch SP. Type 2-diabetes is associated with elevated levels of TNF-alpha, IL-6 and adiponectin and low levels of leptin in a population of Mexican Americans: A cross-sectional study. Cytokine 2012;57:136-142. Epub 2011 Oct 28

10. Gibson RS. Principles of nutritional assessment. 2nd. ed. New York, NY, USA, Oxford University Press, USA, 2005

11. de Onis M, Onyango AW, Borghi E, Siyam A, Nishida C, Siekmann J. Development of a WHO growth reference for school-aged children and adolescents. Bull World Health Organ 2007;85:660-667.

12. Alberti KG, Eckel RH, Grundy SM, Zimmet PZ, Cleeman JI, Donato KA, Fruchart JC, James WP, Loria CM, Smith SC Jr; International Diabetes Federation Task Force on Epidemiology and Prevention; Hational Heart, Lung, and Blood Institute; American Heart Association; World Heart Federation; International Atherosclerosis Society; International Association for the Study of Obesity. Harmonizing the metabolic syndrome: a joint interim statement of the International Diabetes Federation Task Force on Epidemiology and Prevention; National Heart, Lung, and Blood Institute; American Heart Association; World Heart Federation; International Atherosclerosis Society; and International Association for the Study of Obesity. Circulation 2009;120:1640-1645. Epub 2009 Oct 5

13. Grundy SM, Cleeman JI, Daniels SR, Donato KA, Eckel RH, Franklin BA, Gordon DJ, Krauss RM, Savage PJ, Smith SC Jr, Spertus JA, Costa F; American Heart Association; National Heart, Lung, and Blood Institute. Diagnosis and management of the metabolic syndrome: an American Heart Association/National Heart, Lung, and Blood Institute Scientific Statement. Circulation 2005;112:2735-2752. Epub 2005 Sep 12 
14. Matthews DR, Hosker JP, Rudenski AS, Naylor BA, Treacher DF, Turner RC. Homeostasis model assessment: insulin resistance and beta-cell function from fasting plasma glucose and insulin concentrations in man. Diabetologia 1985;28:412-419.

15. Hintze J. NCSS 2007, PASS, and GESS. 2007 ed. Kaysville, Utah, 2007.

16. Wu Y, Yu X, Li Y, Li G, Cheng H, Xiao X, Mi J, Gao S, Willi SM, Li M. Adipose tissue mediates associations of birth weight with glucose metabolism disorders in children. Obesity (Silver Spring) 2019;27:746755. Epub 2019 Feb 27

17. Penha JTD, Gazolla FM, Carvalho CNM, Madeira IR, Rodrigues-Junior F, Machado EA, Sicuro FL, Farinatti P, Bouskela E, Collett-Solberg PF. Physical fitness and activity, metabolic profile, adipokines and endothelial function in children. J Pediatr (Rio J) 2019;95:531-537. Epub 2018 May 30

18. Balagopal PB, de Ferranti SD, Cook S, Daniels SR, Gidding SS, Hayman LL, McCrindle BW, Mietus-Snyder ML, Steinberger J; American Heart Association Committee on Atherosclerosis Hypertension and Obesity in Youth of the Council on Cardiovascular Disease in the Young; Council on Nutrition, Physical Activity and Metabolism; Council on Epidemiology and Prevention. Nontraditional risk factors and biomarkers for cardiovascular disease: mechanistic, research, and clinical considerations for youth: a scientific statement from the American Heart Association. Circulation 2011;123:2749-2769. Epub 2011 May 9

19. Kotnik P, Fischer Posovszky P, Wabitsch M. Endocrine and Metabolic Effects of Adipose Tissue in Children and Adolescents. Zdr Varst 2015;54:131-138.

20. Chen W, Srinivasan SR, Elkasabany A, Berenson GS. Cardiovascular risk factors clustering features of insulin resistance syndrome (Syndrome $\mathrm{X}$ ) in a biracial (Black-White) population of children, adolescents, and young adults: the Bogalusa Heart Study. Am J Epidemiol 1999;150:667674.

21. Goodman E, Daniels SR, Morrison JA, Huang B, Dolan LM. Contrasting prevalence of and demographic disparities in the World Health Organization and National Cholesterol Education Program Adult Treatment Panel III definitions of metabolic syndrome among adolescents. J Pediatr 2004; 145:445-451.

22. Magnussen CG, Koskinen J, Juonala M, Chen W, Srinivasan SR, Sabin MA, Thomson R, Schmidt MD, Nguyen QM, Xu JH, Skilton MR, Kähönen M, Laitinen T, Taittonen L, Lehtimäki T, Rönnemaa T, Viikari JS, Berenson GS, Raitakari OT. A diagnosis of the metabolic syndrome in youth that resolves by adult life is associated with a normalization of high carotid intima-media thickness and type 2 diabetes mellitus risk: the Bogalusa heart and cardiovascular risk in young Finns studies. J Am Coll Cardiol 2012;60:1631-1639. Epub 2012 Sep 26

23. Liu W, Lin R, Liu A, Du L, Chen Q. Prevalence and association between obesity and metabolic syndrome among Chinese elementary school children: a school-based survey. BMC Public Health 2010;10:780.

24. Pedrosa C, Oliveira BM, Albuquerque I, Simoes-Pereira C, Vaz-deAlmeida MD, Correia F. Obesity and metabolic syndrome in 7-9 yearsold Portuguese schoolchildren. Diabetol Metab Syndr 2010;2:40.

25. Li G, Xu L, Zhao Y, Li L, Fu J, Zhang Q, Li N, Xiao X, Li C, Mi J, Gao S, Li M. Leptin-adiponectin imbalance as a marker of metabolic syndrome among Chinese children and adolescents: The BCAMS study. PLOS ONE 2017;12:e0186222.

26. Suarez-Ortegon MF, Aguilar-de Plata C. Prevalence of metabolic syndrome in children aged 5-9 years from southwest colombia: a cross-sectional study. World J Pediatr 2016;12:477-483. Epub 2016 Feb 1

27. Weiss R, Dziura J, Burgert TS, Tamborlane WV, Taksali SE, Yeckel CW, Allen K, Lopes M, Savoye M, Morrison J, Sherwin RS, Caprio S. Obesity and the metabolic syndrome in children and adolescents. N Engl $\mathrm{J}$ Med 2004;350:2362-2374.

28. Saffari F, Jalilolghadr S, Esmailzadehha N, Azinfar P. Metabolic syndrome in a sample of the 6- to 16-year-old overweight or obese pediatric population: a comparison of two definitions. Ther Clin Risk Manag 2012;8:55-63. Epub 2012 Feb 2

29. Marin-Echeverri C, Aristizabal JC, Gallego-Lopera N, Santa-Ramirez HA, Hoyos-Gomez M, Ruiz-Pineda AM, Arias AA, Barona-Acevedo J. Cardiometabolic risk factors in preschool children with abdominal obesity from Medellin, Colombia. J Pediatr Endocrinol Metab 2018;31:1179-1189.

30. Mi J, Munkonda MN, Li M, Zhang MX, Zhao XY, Fouejeu PC, Cianflone K. Adiponectin and leptin metabolic biomarkers in chinese children and adolescents. J Obes 2010;2010:892081. Epub 2010 Oct 31

31. Cizmecioğlu FM, Hatun S, Kalaça S. Metabolic syndrome in obese Turkish children and adolescents: comparison of two diagnostic models. Turk J Pediatr 2008;50:359-365.

32. Nigro E, Scudiero O, Ludovica Monaco M, Polito R, Schettino P, Grandone A, Perrone L, Miraglia Del Giudice E, Daniele A. Adiponectin profile and Irisin expression in Italian obese children: Association with insulin-resistance. Cytokine 2017;94:8-13. Epub 2017 Apr 3

33. Kim YM, Kim SH, Shim YS. Associations of non-high-density lipoprotein cholesterol with metabolic syndrome and its components in Korean children and adolescents: the Korea National Health and Nutrition Examination Surveys 2008-2014. World J Pediatr 2018;14:461-469. Epub 2018 Jul 24

34. Bacha F, Saad R, Gungor N, Arslanian SA. Adiponectin in youth: relationship to visceral adiposity, insulin sensitivity, and beta-cell function. Diabetes Care 2004;27:547-552.

35. Ramkumar S, Tandon N. Type 2 diabetes mellitus in children and youth. Indian J Pediatr 2013;80(Suppl 1):87-94. Epub 2013 Feb 21

36. Madeira IR, Carvalho CN, Gazolla FM, Pinto LW, Borges MA, Bordallo MA. Impact of obesity on metabolic syndrome components and adipokines in prepubertal children. J Pediatr (Rio J) 2009;85:261-268. Epub 2009 Feb 10

37. Hulver MW, Dohm GL. The molecular mechanism linking muscle fat accumulation to insulin resistance. Proc Nutr Soc 2004;63:375-380.

38. Mosimah CI, Lilly C, Forbin AN, Murray PJ, Pyles L, Elliot E, Neal W. Early testing of insulin resistance: a tale of two lipid ratios in a group of 5 th graders screened by the Coronary Artery Risk Detection in Appalachian Communities Project (CARDIAC Project). World J Pediatr 2019;15:398-404. Epub 2019 May 4

39. Cruz M, Garcia-Macedo R, Garcia-Valerio Y, Gutierrez M, Medina-Navarro R, Duran G, Wacher N, Kumate J. Low adiponectin levels predict type 2 diabetes in Mexican children. Diabetes care 2004;27:1451-1453.

40. Volberg V, Heggeseth B, Harley K, Huen K, Yousefi P, Davé V, Tyler K, Vedar M, Eskenazi B, Holland N. Adiponectin and leptin trajectories in Mexican-American children from birth to 9 years of age. PLoS ONE 2013;8:e77964

41. Du Y, Zhang T, Sun D, Li C, Bazzano L, Qi L, Krousel-Wood M, He J, Whelton PK, Chen W, Li S. Effect of serum adiponectin levels on the association between childhood body mass index and adulthood carotid intima-media thickness. Am J Cardiol 2018;121:579-583. Epub 2017 Dec 12

42. Araki S, Dobashi K, Kubo K, Asayama K, Shirahata A. High molecular weight, rather than total, adiponectin levels better reflect metabolic abnormalities associated with childhood obesity. J Clin Endocrinol Metab 2006;91:5113-5116. Epub 2006 Sep 19

43. McCourt HJ, Hunter SJ, Cardwell CR, Young IS, Murray LJ, Boreham CA, McEneny J, Woodside JV, McKinley MC. Adiponectin multimers, body 
weight and markers of cardiovascular risk in adolescence: Northern Ireland Young Hearts Project. Int J Obes 2013;37:1247-1253. Epub 2013 Jan 15

44. Butte NF, Comuzzie AG, Cai G, Cole SA, Mehta NR, Bacino CA. Genetic and environmental factors influencing fasting serum adiponectin in Hispanic children. J Clin Endocrinol Metab 2005;90:4170-4176. Epub 2005 Apr 12

45. Punthakee Z, Delvin EE, O'Loughlin J, Paradis G, Levy E, Platt RW, Lambert M. Adiponectin, adiposity, and insulin resistance in children and adolescents. J Clin Endocrinol Metab 2006;91:2119-2125. Epub 2006 Mar 14

46. Murdolo G, Nowotny B, Celi F, Donati M, Bini V, Papi F, Gornitzka G, Castellani S, Roden M, Falorni A, Herder C, Falorni A. Inflammatory adipokines, high molecular weight adiponectin, and insulin resistance: a population-based survey in prepubertal schoolchildren. PLoS One 2011;6:e17264.

47. Eslamian M, Mohammadinejad P, Aryan Z, Nakhjavani M, Esteghamati A. Positive Correlation of Serum Adiponectin with Lipid Profile in
Patients with Type 2 Diabetes Mellitus is Affected by Metabolic Syndrome Status. Arch Iran Med 2016;19:269-274.

48. Martos-Moreno GA, Barrios V, Martinez G, Hawkins F, Argente J. Effect of weight loss on high-molecular weight adiponectin in obese children. Obesity (Silver Spring) 2010;18:2288-2294. Epub 2010 Mar 25

49. Bush NC, Darnell BE, Oster RA, Goran MI, Gower BA. Adiponectin is lower among African Americans and is independently related to insulin sensitivity in children and adolescents. Diabetes 2005;54:2772-2778.

50. Lara-Castro C, Doud EC, Tapia PC, Munoz AJ, Fernandez JR, Hunter GR, Gower BA, Garvey WT. Adiponectin multimers and metabolic syndrome traits: relative adiponectin resistance in African Americans. Obesity (Silver Spring) 2008;16:2616-2623. Epub 2008 Sep 2551.

51. Takemoto K, Deckelbaum RJ, Saito I, Likitmaskul S, Morandi A, Pinelli L, Ishii E, Kida K, Abdalla M. Adiponectin/resistin levels and insulin resistance in children: a four country comparison study. Int J Pediatr Endocrinol 2015;2015-2. Epub 2015 Jan 15 